\title{
PERANAN PRODUK WISATA DAN BRAND STRATEGY TERHADAP MINAT KUNJUNGAN WISATAWAN DI THE HERRITAGE PALACE SUKOHARJO
}

\author{
Kris Cahyani Ermawati \\ Sekolah Tinggi Pariwisata Sahid Surakarta \\ kriscahyani@gmail.com
}

\begin{abstract}
This study aims to determine tourism products and brand strategy on the interest of tourists visiting The Herriatge Palace Sukoharjo. The writing of this report is presented in a qualitative descriptive manner to obtain an overview of information related to tourism products and brand strategy on the interest of tourists visiting The Herriatge Palace. The method used in this research is interviews, observation, documentation and literature study, and uses data triangulation analysis. The results showed that the tourism products of The Herritage Palace have historical and man-made tourist attractions which are identified based on the attraction components, the amenities provided are complete and make it easier for visitors during their tour. The available accessibility makes it easier for visitors to get to the location. Ancilary has done its job well. The Herriatge Palace brand identity strategy is implemented through the logo and tagline. The brand personality that The Herritage Palace wants to build is based on its personality, namely the excitement character. The brand communication strategy carried out by The Herriatge Palace Sukoharjo is collaboration with other companies by exchanging promo materials and utilizing social media. The conclusion of this study is that The Herritage Palace's tourism products have fulfilled four components, namely attraction, amenity, accessibility, and ancillary. The existence of these four components and the added brand strategy carried out by the manager makes this tourist spot in great demand by tourists.
\end{abstract}

Keywords: Tourism Products, Brand Strategy, and The Herriage Palace

\section{PENDAHULUAN}

Beraneka ragam budaya Indonesia berupa bahasa daerah, adat istiadat, tradisi, bangunan sejarah, bangunan cagar budaya dan lainnya memberikan keunikan untuk Indonesia. Keunikan tersebut menjadi suatu potensi yang dapat dikembangkan menjadi sesuatu yang menarik untuk diketahui dan dipelajari. Hal tersebut juga dapat dikembangkan untuk kegiatan pariwisata. Ada banyak daya tarik wisata yang sudah memanfaatkan dan mengembangkan potensi budaya yang dimiliki oleh masing-masing daya tarik wisata.

Produk destinasi maupun daya tarik wisata dapat dikomunikasikan kepada calon 
pengunjung maupun wisatawan dengan dibuatnya sebuah branding. Dalam pembuatan branding, pengelola perlu mengetahui bagaimana suatu daya tarik wisata maupun destinasi ingin dikenal. Hal tersebut sangat erat kaitannya dengan potensi utama yang dimiliki oleh suatu daya tarik wisata, potensi yang dikembangkan atau diwujudkan oleh sebuah produk wisata, dapat berupa atraksi dan aktifitas wisata (Pradipta, 2021). Sehingga yang diharapkan dari suatu branding yaitu, bisa memberikan penggambaran secara umum mengenai suatu daya tarik wisata. Ketika calon wisatawan atau pengunjung yang baru mengetahui atau mendengar suatu branding, mereka sudah mengetahui apa yang ada ditempat yang dimaksud dan aktifitas apa saja yang sekiranya dapat mereka lakukan.

Suatu daya tarik wisata maupun destinasi perlu diberikan branding untuk menunjukkan ciri khas dan keunikan suatu daya tarik wisata dan sebagai pembeda dengan daya tarik wisata lain. Semakin unik dan khas suatu potensi wisata yang di branding, diharapkan dapat memenuhi antara ekspektasi wisatawan dengan produk wisata yang disediakan. Sehingga dapat meningkatkan kepercayaan dan kepuasan mereka. Banyaknya destinasi yang mempunyai karakterisrtik potensi wisata yang sama maupun berbeda, akan menimbulkan suatu persaingan untuk menarik wisatawan berkunjung, sehingga dengan adanya branding dapat menjadi sebagai pembeda dengan daya tarik lainnya.

Suatu branding sebaiknya dibuat unik dan mudah diingat oleh setiap orang yang baru pertama kali mengetahui atau mendengarnya. Hal tersebut dilakukan sebagai bentuk mempromosikannya kepada masyarakat luas. Semakin branding mudah diingat, setidaknya memudahkan pihak pengelola untuk memperkenalkan suatu daya tarik wista yang sedang dikelola. Membangun sebuah branding membutuhkan waktu yang tidak singkat, dibutuhkan suatu proses yang lama untuk keberhasilan suatu branding, sehingga kegiatan promosi yang dilakukan dengan memperkenalkan suatu brand memberikan dampak jangka panjang.

Kabupaten Sukoharjo juga memiliki bangunan bersejarah berupa bekas pabrik gula Gembongan yang dibangun pada zaman colonial Belanda, sehingga bangunannya bernuansa eropa klasik.

Pabrik Gula Gembongan bukan merupakan bangunan milik BUMN, melainkan milik swasta yang dikelola oleh PT. Gendhis Mas Sentosa Abadhi. Pabrik Gula Gembongan memiliki luas 2,2 hektar dengan sembilan gedung. Pihak pengelola 
kini mengembangkan bangunan bekas pabrik gula tersebut sebagai suatu daya tarik wisata baru di Kabupaten Sukoharjo, yang bernama The Herritage Palace. Bangunan pabrik yang masih memiliki nuansa eropa klasik tersebut menjadi daya tarik utama dalam mengembangakannya menjadi suatu daya tarik wisata.

Pengelola The Heritage Palace mengemas tempat tersebut menjadi daya tarik wisata dengan aktifitas utamanya untuk berfoto. Pada setiap area memiliki tema dan konsep spot foto yang berbeda-beda. Setidaknya terdapat 6 area spot berfoto dengan tema yang menarik, yaitu museum transportasi, museum 3D, omah kwalik, café kopi, jembatan, dan taman. Selain tempat berfoto yang menjadi produk wisata, pengelola juga memiliki produk wisata lain berupa penyewaan gedung untuk dijadikan tempat penyelenggaraaan berbagai acara seperti produk branding, prewedding, wedding, birthday, exhibition, gala dinner dan partnership.

Selain itu, pengelola juga mempunyai tag line yaitu "tempat selfie sepuas-puasnya". Dari tagline tersebut, seakan memberikan makna dan informasi bahwa The Herritage Palace adalah tempat yang menarik dan cocok untuk berselfie. Berdasarkan latar belakang diatas, penulis tertarik untuk melakukan penelitian dengan judul "Peranan Produk Wisata dan Brand Strategi Terhadap Minat Kunjungan Wisatawan di The Herritage Palace Sukoharjo".

Dari latar belakang masalah diatas, peneliti melakukan penelitian tentang bagaimana peranan produk wisata dan brand strategy terhadap minat kunjungan wisatawan di The Herritage Palace Sukoharjo? Tujuan penelitian dari penulisan ini adalah untuk mengetahui peranan produk wisata dan brand strategy terhadap minat kunjungan wisatawan di The Herritage Palace Sukoharjo.

Menurut Manahti Zebua (2016:32) menjelaskan bahwa pengertian produk wisata yaitu segala jenis produk, baik berbentuk barang maupun jasa yang merupakan suatu komoditas pariwisata. Produk wisata yang dimaksud dapat memenuhi keinginan dalam kebutuhan untuk rekreasi, bisnis, pengembangan pribadi dan keingintahuan mereka pada keunikan alam serta budaya masyarakat setempat. Oleh sebab itu, produk wisata dapat direalisasikan melalui disediakannya berbagai daya tarik wisata, fasilitas yang diperlukan, transportasi dan jenis usaha lainnya yang dapat memenuhi kebutuhan wisatawan. 
Ada 4 komponen dalam produk wisata, antara lain: Attraction (tersedianya daya tarik pada suatu daerah tujuan wisata atau destinasi wisata untuk menarik wisatawan berkunjung), Accesibility (tersedianya alat-alat transportasi untuk memudahkan wisatawan domestik maupun mancanegara untuk mengunjungi suatu daya tarik wisata, Amenitas (tersedianya fasilitas utama maupun pendukung pada destinasi wisata berupa akomodasi, restoran, pusat oleh-oleh), Ancilary (adanya lembaga penyelenggara perjalanan wisatawan sehingga kegiatan wisata dapat berlangsung).

Yudho Yudhanto (2018:150) menjelaskan bahwa bermanfaat bagi pelaku usaha dan konsumen. Setidaknya terdapat empat fungsi dari suatu brand, yaitu sebagai penanda; promosi dan daya tarik; membangun citra, keyakinan, jaminan kualitas, dan prestise; serta pengendalian pasar.

Jenis branding dibedakan menjadi dua, yaitu product branding dan personal branding. Product branding bertujuan untuk mempengaruhi konsumen agar lebih memilih produk yang sedang kita branding, sedangkan Personal branding merupakan alat pemasaran yang digunakan untuk mengangkat nama seorang publik figur.
Menurut Fera Kusno (2007:44) menjelaskan bahwa brand strategy artinya strategi merek mendefinisikan apa yang seharusnya dicapai suatu brand dalam kaitannya dengan sikap dan perilaku konsumen. Komponen yang termasuk ke dalam brand strategy antara lain brand positioning, brand identity, dan brand personality.

Wisatawan adalah orang-orang yang mengadakan perjalanan kesuatu negara atau daerah yang bukan daerah dimana ia tinggal dengan tujuan untuk tidak menetap atau tidak bekerja dan membelanjakan uangnya ditempat tersebut (Parwestri 2014:14). Definisi wisatawan menurut Suryadana dan Octativa (2015:36). Seorang wisatawan adalah seorang yang memasuki wilayah negeri asing dengan maksud tujuan apapun, asalkan bukan untuk tinggal permanen atau untuk usaha.

\section{METODE}

Penelitian ini menggunakan metode kualitatif yang disajikan secara deskriptif, yaitu menggambarkan obyek yang diamati secara jelas dan terperinci. Metode deskriptif merupakan suatu metode penelitian yang bertujuan untuk menggambarkan fenomena yang sedang terjadi, atau yang sudah terjadi. 
Penelitian deskriptif bisa mendeskripsikan suatu keadaan saja, tapi juga bisa mendeskripsikan keadaan secara bertahap untuk menjelaskan perkembangannya (Eko Sugiarto, 2015: 89). Populasi adalah keseluruhan dari obyek penelitian (Asep Saepul Hamdi dan E. bahrudin, 2014:38). Penulis menetapkan populasi dalam penelitian ini adalah pengelola dan karyawan The Herritage Palace.

Sampel adalah bagian dari jumlah populasi yang diteliti, sehingga hasil penelitian bisa digeneralisasikan. Penulis menetapkan sampel dalam penelitian ini adalah pihak pengelola dan karyawan The Herritage Palace.

Data primer adalah informasi yang diperoleh dari sumber primer melalui observasi dan wawancara atau informasi dari tangan pertama atau narasumber (Eko Sugiarto, 2015:87). Data primer dalam penelitian ini diperoleh peneliti dari observasi dan informan yang terkait dengan The Herriatge Palace.

Data sekunder adalah informasi yang diperoleh secara tidak langsung dari narasumber, melainkan dari pihak ketiga (Eko Sugiarto, 2015:87). Data sekunder diperoleh peneliti dari literature dan hasil penelitian yang terkait dengan The Herritage Palace.

Teknik pengumpulan data menggunakan wawancara, observasi studi pustaka, dan dokumentasi. Wawancara merupakan tahapan proses tanya jawab dalam suatu penelitian yang berlangsung secara lisan dimana dua orang atau lebih bertatap muka, mendengarkan secara langsung informasi-informasi atau keterangan-keterangan (Cholid dan Abu Achmadi, 2003:83). Dari wawancara ini akan di dapatkan data-data yang berkaitan dengan tema yang diangkat dalam penelitian. Wawancara dilakukan kepada Bapak Franky selaku pengelola The Herriage Palace. Observasi artinya mengumpulkan data yang diambil langsung dari lapangan. Observasi yang dilakukan oleh penulis untuk mendapatkan gambaran secara nyata dan jelas mengenai produk wisata yang disediakan The Herritage Palace. Metode studi pustaka ini dilaksanakan dengan cara mengumpulkan data dari berbagai literature melalui buku, internet, maupun sumber-sumber lainnya yang memiliki konsep dengan kajian serta berkaitan dengan judul sebagai bahan acuan dalam mengumpulkan data (Budi Purnomo, 2015:67). Studi dokumentasi merupakan salah satu teknik pengumpulan data dengan 
cara memproleh informasi dari berbagai macam sumber tertulis atau dokumen yang ada pada responden dimana responden melakukan kegiatan kesehariannya. Dokumen dapat berbentuk tulisan seperti logbook, gambar atau karya monumental dari seseorang seperti buku, lukisan, bangunan dan patung (Budi Purnomo, 2015:67).

Menurut Bachtiar S. Bachri (2010:50) menjelaskan bahwa Triangulasi adalah suatu cara mendapatkan data dengan menggunakan pendekatan metode ganda. Triangulasi adalah teknik pemeriksaan keabsahan data dengan cara memanfaatkan sesuatu yang lain di luar data itu sendiri, untuk keperluan pengecekan atau sebagai pebanding terhadap data itu sendiri.

\section{HASIL PENELITIAN DAN PEMBAHASAN}

\section{Hasil Penelitian}

Produk wisata yang dimiliki oleh The Herritage Palace terbagi menjadi tiga macam yaitu atraksi wisata buatan manusia, atraksi wisata sejarah, dan penawaran paket penyewaan convention hall untuk penyelenggaraan berbagai acara.

\section{Produk wisata di The Heritage Palace} Atraksi
Berdasarkan observasi dan wawancara dengan pihak pengelola, attraction di The Herritage Palace terdiri dari daya tarik wisata sejarah, buatan manusia, dan penyewaan concention hall. Daya tarik wisata sejarah berupa bangunan gedung dari PG. Gembongan yang merupakan bekas pabrik gula pada tahun 1890 dan museum transportasi yang menampilkan koleksi mobil-mobil antik. Daya tarik buatan manusia yaitu berupa area time zone, museum tiga dimensi dan omah kwalik. Serta penyewaan convention hall berupa penawaran paket birthday party, gala dinner, meeting, konser, wedding, dan gathering. Menurut pihak pengelola bahwa atraksi utama di The Herritage Palace yaitu keindahan bangunan PG. Gembongan yang berada di area taman.

Bapak franky selaku pengelola The Herritage Palace juga menyatakan bahwa gedung dari PG. Gembongan dinilai sangat indah yang tidak dimiliki oleh tempat lain, kemudian dalam penentuan produk wisata, beliau juga memasukkan sisi modernnya untuk kalangan milenial, remaja penghoby fotograpy. Bangunan ini juga dimanfaatkan untuk convention hall yang disewakan untuk penyelenggaraan berbagai acara sehingga disediakan berbagai macam paket.

1. Amenitas

Amenitas berupa penyediaan fasilitas yang bertujuan untuk memudahkan pengunjung ketika berada di The Herritage Palace. Berdasarkan wawancara dengan pihak pengelola, amenitas yang tersedia di The Herritage Palace sudah lengkap dan sudah layak untuk suatu daya tarik wisata. Amenitas yang tersedia, terdiri dari area parkir, loket pembelian tiket, food center, 
papan petunjuk, pos security, merchandise, toilet, mushola, fotografer, sampel foto, dan peta denah lokasi.

\section{Accesibilitas}

Aksesibilitas atau akses menuju The Herritage Palace sudah sangat terjangkau. Akses jalan sudah beraspal dan lokasi dekat dari jalan raya Solo-Yogyakarta, bisa di akses dari jalur darat dan udara. Kondisi jalan bisa dikases oleh berbagai kendaraan seperti motor, mobil, bus, dan elf. Selain kendaraan pribadi, The Herritage Palace juga dapat diakses dengan kendaraan umum seperti BST dan bis dengan rute SoloYogyakarta maupun sebaliknya

\section{Ancilary}

Ancilary yaitu terkait dengan pengelolaan di The Herritage Palace yang dibagi menjadi 9 departemen yaitu, pengelola, HRD, Finance, Administrasi, Operasional, Security, Petugas parkir dan petugas kebersihan.

\section{Strategi Branding The Herritage Palace}

\section{Brand Positioning}

Berdasarkan hasil observasi dan wawancara dengan pihak pengelola, pihak pengelola ingin menanamkan dalam benak konsumen bahwa The Herritage Palace dalah bekas pabrik gula Gembongan yang memiliki bangunan gaya arsitektur eropa, selain itu masih terjaga kelestarian dan keasliannya yang terlihat megah, sehingga perlu dikunjungi. Selain itu, pihak pengelola juga ingin menanamkan dibenak para pengunjung bahwa The Herritage Palace ini adalah tempat yang menarik untuk dijadikan tempat berfoto.
Berdasarkan jenis produk wisata yang dimiliki oleh The Herritage Palace, cara positioning yang dilakukan yaitu berdasarkan kategori produk.

\section{Brand Identity}

Strategi pihak pengelola The Herritage Palace untuk menyampaikan brand identity nya yaitu melalui logo dan tagline. Obyek tulisan The Herritage Palace pada logo sudah mewakili sebagai obyek yang dilihat sebagai satu kelompok tersendiri. Ornamen yang terpisah-pisah pada logo The Herritage Palace menggambarkan arsitektur pada puncak dinding bangunan PG. Gembongan. Background ornament yang berada di atas tulisan "The Herritage Palace" dapat dilihat sebagai rangkaian huruf The Herritage Palace. Logo cenderung berbentuk dua dimensi. Berdasarkan analisis logo yang sudah dilakukan, logo tersebut sudah menggambarkan atau mewakili sebagai identitas The Herritage Palace.

Tag line adalah salah satu atribut dalam sistem identitas, berupa satu kata atau lebih yang menggambarkan esensi, personality, maupun positioning brand. Kalimat yang digunakan sebagai tag line The Herritage Palace yaitu "Wahana Wisata Keluarga dan "Tempat Selfie Sepuas-puasnya" Kalimat Wahana Wisata Keluarga biasanya diletakan disamping logo. Berdasarkan wawancara dengan bapak Franky, tag line Wahana Wisata Keluarga ini maksudnya adalah pangsa pasar dari wisata The Herritage Palace ini adalah keluarga dengan konsep family fun. Sedangkan tag line "Tempat Selfie Sepuas-puasnya" yaitu seakan menginformasikan bahwa The Herritage Palace merupakan tempat yang 
instagramable untuk dijadikan lokasi berfoto, karena memiliki banyak spot foto yang beraneka ragam.

\section{Brand Personality}

Brand Personality yang ingin dibangun oleh The Herritage Palace yaitu karakter excitement (kegembiraan). Produk wisata The Herritage Palace memenuhi beberapa karakter sebagai berikut:

\section{- Keunikan}

The Herritage Palace mempunyai atraksi wisata yang unik berupa bangunan indah dengan arsitektur bergaya eropa yang jarang dimiliki oleh tempat lain.

- Imajinatif

Produk wisata The Herritage Palace yang memerlukan imajinasi untuk menikmatinya yaitu ketika pengunjung mengambil foto di museum tiga dimensi dan omah kwalik.

- Berjiwa muda

Atraksi wisata yang dimiliki oleh The Herritage Palace dikemas oleh pengelola untuk kaum milenial, diberikan sisi modern yang identik dengan gaya anak muda.

\section{- Bersemangat dan antusias}

Pengunjung yang menikmati wisata di The Herritage Palace akan dibuat antuasias terhadap atraksi wisata yang dimiliki sehingga bersemangat untuk mengeksplore tempat tersebut.

\section{Brand Communication}

Brand Communication yang dilakukan oleh pihak pengelola The Herritage Palace yaitu bertukar materi promo dengan perusahaan lain, yang nantinya akan di cetak atau dipromosikan pada perusahaan masingmasing melalui banner maupun brosur; memanfaatkan media sosial seperti instagram, facebook, website, dan youtoube.

\section{Kesimpulan}

Produk wisata The Herritage Palace yang diidentifikasi berdasarkan komponen attraction, merupakan suatu daya tarik wisata sejarah, buatan manusia dan event. Daya tarik wisata sejarah berupa bangunan bekas PG. Gembongan dan Museum Transportasi. Daya tarik wisata buatan manusia berupa penyediaan spot foto di Museum Tiga Dimensi dan Omah Kwalik. Sedangkan daya tarik event yaitu penyewaan convention hall untuk penyelenggaraan berbagai acara yang ditawarkan berupa paket meeting, birthday party, konser, gala dinner, wedding, dll. Amenity atau fasilitas yang disediakan dinilai sudah lengkap dan memudahkan pengunjung ketika berada di The Herritage Palace. Fasilitas yang disediakan yaitu penyediaan area parkir, loket pembelian tiket, pos security, papan petunjuk dan informasi, jasa fotografer, tempat pembelian merchandise, toilet, mushola, food center, dan sample foto. Accesibilitas menuju the Herritage Palace dinilai sudah memudahkan pengunjung untuk mencapai tempat tersebut. Accesibiltas yang memudahkan pengunjung yaitu akses jalan sudah beraspal, mudah diakses kendaraan umum maupun pribadi, dan lokasi dekat dekat dengan bandara Adisumarmo. Ancilary yaitu terkait dengan pengelolaan di The Herritage Palace yang dibagi menjadi 9 departemen yaitu, pengelola, HRD, Finance, Administrasi, Operasional, Security, Petugas parker dan petugas kebersihan. 
Brand Strategy yang dilakukan oleh pihak pengelola The Herritage Palace diidentifikasi berdasarkan empat aspek, yaitu brand positioning, brand identity, brand personality, brand communication. Strategi brand positioning oleh The Herritage Palace yaitu penentuan positioning berdasarkan kategori produk. Produk wisata yang dimiliki oleh The Herritage Palace menjadi pembeda dari produk wisata lain. Strategi brand identity oleh The Herritage Palace yaitu melalui logo, dan tagline. Tagline The Herritage Palace yaitu "Wahana Wisata Keluarga" dan "Tempat Berselfi Sepuas-puasnya". Tagline tersebut dipilih untuk memggambarkan esensi dari produk wisata yang dimiliki dan sebagai brand positioning. Brand personality yang ingin dibangun oleh The Herritage Palace berdasarkan kepribadiannya yaitu karakter excitement (kegembiraan). Karakter excitement menggambarkan produk wisata yang dimiliki oleh The Herritage Palace memiliki keunikan, imajinatif, berjiwa muda, bersemangat, dan antusias. Strategi brand communication yang dilakukan oleh the Herritage Palace yaitu dengan bekerjasama dengan perusahaan lain dengan bertukar materi promo serta menggunakan media sosial instagram, facebook, dan website.

\section{REFERENCES}

Aniesa Samira Bafadhal. 2018. Perencanaan Bisnis Pariwisata. Malang: UB Press.

Asep Saepul Hamdi dan E. Bahruddin. 2014. Metode Penelitian Kuantitatif Aplikasi dalam Pendidikan. Yogyakarta. Deepublish.

Bachtiar S. Bachri. 2010. Menyakinkan validitas Data Melalui Triangulasi Pada Penelitian Kualitatif. Jurnal Teknologi Pendidikan. Vol.10 No.1: 46-62.

Bambang Sunaryo. 2013. Kebijakan Pembangunan Destinasi Pariwisata Konsep dan Aplikasinya di Indonesia. Yogyakarta: Gava Media.

Budi Purnomo. 2015. Metode Penelitian Pariwisata. Yogyakarta: K Media

Eko Sugiarto. 2015. Menysusun Proposal Penelitian Kualitatif: Skripsi dan Tesis. Yogykarta: Suaka Media.

Fera Kusno, Amanda Radityani dan Monika Kristanti. 2007. Analisa Hubungan Brand Strategy yang Dilakukan Goota Japanese Charcoal Grill and Café dan Brand Equity Yang Sudah Diterima Konsumen. Jurnal Manajemen Perhotelan, Vol. 3 No. 1: 43-56.

I Gusti bagus Rai Utama. 2014. Pengantar Industri Pariwisata. Yogyakarta. Deepublish.

Ismayanti. 2010. Pengantar Pariwisata. Jakarta: Grasindo.

June Cahyaningtyas dan Sri Issundari. 2016. Place Branding dalam hubungan Internasional. Yogyakarta: Depublish Manhati Zebua. 2016. Inspirasi Pengembangan Pariwisata Daerah. Yogyakarta: Depublish.

Pradipta, M. P. Y. (2021). Pariwisata Berbasis Masyarakat Sebagai Pelestari Tradisi Di Desa Samiran. Jurnal Kepariwisataan, 5(1), 99-109. https://doi.org/10.34013/jk.v5i1.379 
Jurnal Pariwisata dan Budaya

Volume 2 Nomor 2 Desember 2021

Rhenald Kasali. 2007. Membidik Pasar

Informasi. Yogyakarta: CV. Andi Indonesia, Segmentasi, targeting, Offset.

Positioning. Jakarta: PT.Gramedia Pustaka Utama.

Yudho Yudhanto. 2018. Information Technology Bussines Start Up. Shofwan hanif dan Dian Pramana. 2010. Pariwisata dengan media Sistem Jakarta: PT. Elex Media Komputindo. 